\title{
Service learning in pharmacy: implementation of tuberculosis screening by second-year pharmacy students in primary health care facilities in Cape Town, South Africa
}

\author{
Adeleye T. Adeola (iD), Renier Coetzee (iD), Mea van Huyssteen (iD), Angeni Bheekie (iD) \\ School of Pharmacy, University of the Western Cape, Bellville, Cape Town 7535, South Africa
}

\author{
Keywords \\ Nurses \\ Pharmacy students \\ PHC facilities \\ Service learning in pharmacy \\ Tuberculosis screening

\section{Correspondence} \\ Mea van Huyssteen \\ School of Pharmacy \\ University of the Western Cape \\ Private bag X17 \\ Bellville \\ Cape Town 7535 \\ South Africa \\ mvanhuyssteen@uwc.ac.za
}

\begin{abstract}
Background: The School of Pharmacy of the University of the Western Cape implemented a service learning programme where second year students participated in tuberculosis (TB) screening. Objectives: To determine the views of students and nurses about student-led TB screening at primary healthcare (PHC) facilities. Methods: The study was descriptive and quantitative. The target populations were pharmacy students and nurses, who completed self-administered semi-structured questionnaires. Results: Study participants included 99 students from 19 facilities and 38 nurses who represented 15 facilities. Students had screened 1323 patients and referred 210 for further testing. Students and nurses felt students were adequately trained to conduct TB screening and seemed to screen patients with ease. Students and nurses believed that students gained more TB knowledge and clinical experience. Students also believed the TB screenings were beneficial to the patients and nurses. Conclusion: Students and nurses perceived the outcomes of student-led TB screening to be mostly positive.
\end{abstract}

\section{Introduction}

Tuberculosis (TB) is a global health concern, with an estimated 1.451 million people dying from TB in 2018 globally (World Health Organization, 2019). South Africa was one of eight countries that accounted for two-thirds of the global TB cases in 2018 (World Health Organization, 2019). TB (together with HIV) is one of the arms of the so-called quadruple burden of disease in South Africa. About 301,000 people fell ill with TB in South Africa in 2018, and a total of 63,000 died (World Health Organization, 2019), despite it being curable and preventable.

The central pillars of TB control had been identified as finding, treating and preventing infection in order to avoid deaths and reduce transmission (Churchyard et al., 2014). Earlier case detection with improved access to anti-tuberculosis therapy is a key objective of the World Health Organization's (WHO) End TB campaign (Calligaro et al., 2017). TB screening is the starting point for any intervention in TB control. Different countries have different screening methods for active or latent tuberculosis, which depends on the TB prevalence in the population. High burden countries, like South Africa, use symptom-based screening to identify the active disease and low burden counties such as the United States of America (USA) use the tuberculin skin test to identify the latent disease (McKennon \& Arnold, 2016).

However, in South Africa, TB screening and active case finding approaches have not been rolled out very effectively. Case detection rates reported being as low as $50 \%$ in high burden settings such as some communities in Cape Town (Calligaro et al., 2017). 
Indeed, literature indicated that patients with TB were 'missed' in primary healthcare (PHC) facilities in South Africa either as a result of not screening for symptoms or if screened not being tested (Claasens et al., 2013; Kweza et al., 2018). In addition, TB infection control was found to be poor in 114 out of 158 PHC facilities across South Africa, and this might be linked to the wider crises within the health system where overstretched nurses at understaffed clinics lack the capacity and resources to engage effectively in infection control measures (Rutter, 2017). In addition, TB treatment in South Africa is provided by the public health care system, which operates as a vertical programme, being conducted primarily by nurses with minimal integration with the rest of the health care team (Coovadia et al., 2009; Churchyard et al., 2014). While studies show that pharmacists from high burden communities indicate strong support to participate in TB programmes (Daftary et al., 2017a), to date, however, pharmacists' contributions have been restricted to their traditional role as 'drug dispensers, or at best to serve as treatment supervisors under the directly observed therapy framework (Miller \& Goodman, 2020).

Symptomatic screening for TB is a low-cost venture and requires low expertise to perform. Literature from TB screening and referral interventions involving community pharmacists in high burden countries has shown promising results (Colvin et al., 2014; Daftary et al., 2019; Miller \& Goodman, 2020). Indeed, a study from the USA found that second-year pharmacy students who received certification in TB screening (using the tuberculin skin test) could screen patients for TB very effectively and accurately (McKennon \& Arnold, 2016). This then begs the question, how could pharmacy students be incorporated into the TB control/screening team in primary care facilities in South Africa? One approach is to engage pharmacy students in a service-learning programme to screen patients for TB.

Since 2013, the School of Pharmacy of the University of the Western Cape has been expanding its servicelearning in pharmacy (SLiP) programme from the first year of study. Its primary aim is to provide relevant learning opportunities for students based on local health needs (van Huyssteen \& Bheekie, 2015). As part of the second-year programme, TB screening in PHC clinics was implemented (2014), which is in accordance with the South African Department of Health's proposed clinic-based programme, which requires TB screening for all clinic attendees (McCreesh et al., 2016). Pharmacy students are required to fulfil a service-learning requirement at $\mathrm{PHC}$ facilities by screening patients for TB and referring those who require confirmation of the diagnosis to nursing staff.
Indeed, local studies on undiagnosed TB and missed TB cases in clinics support this universal approach to active case finding in PHC facilities (Claasens et al., 2016; Kweza et al., 2018).

The aim of this study was to assess the implementation of student-led TB screening as part of the second year service-learning programme in public PHC facilities in the Cape Town Metropole area. The perceptions of the participating students and nurses and the students' TB screening reports were used to gauge the perceived outcomes of the TB screening on patients, the facility, and students' learning and professional skills development.

\section{Methods}

The study was descriptive and quantitative in nature. Approval to conduct the study was obtained from the University of the Western Cape Biomedical Research Ethics Committee (registration number BM/16/4/08) and permission to access the facilities for data collection from the City of Cape Town Research Committee (registration number 7754).

\section{Study setting}

Second-year pharmacy students at the University of the Western Cape are required to apply their knowledge obtained during on-campus activities of the clinical pharmacy and pharmacology module (PHC213) as part of the service-learning in pharmacy (SLiP) programme. Students are required to undertake their service activities at PHC facilities located within the Northern and Tygerberg sub-districts of the City of Cape Town health services under the supervision of nurses employed at these facilities. Each year, about 21 PHC facilities participate in the SLiP programme, which operates on a formal memorandum of agreement between the School and City Health Department (revised in 2019). As such, students are divided into groups (average 3 per group) and assigned to a PHC facility. Each student group attends their designated facility for three consecutive Friday mornings for 3 hours during the first semester (February to April).

The learning objectives for students in this programme included: 1) providing a TB screening service to the clinic, which entailed TB screening and patient education regarding TB testing and prevention; 2) developing students' communication skills through actual interactions with patients and; 3) interacting with nurses (interdisciplinary interaction) to obtain insight and an appreciation for the nurse's scope of practice in the health care system. A week prior to student groups arriving at the PHC facilities, faculty 
members conducted a campus-based orientation session for the entire class. Students were informed about the spectrum of clinic services, trained on the use of the symptom-based TB screening tool, and were specifically required to follow an infection prevention and control (IPC) protocol upon entry into the clinic. The three aspects of IPC included administrative (identify coughing patients and fast-track them through the facility), environmental (adequate ventilation in screening location), and personal respiratory (personal protection such as wearing of face-masks, cough etiquette, good hygiene practice) controls. Students were informed that they should preferably screen patients in the general waiting room and not in the facility's designated TB waiting room to minimise their risk of TB exposure. Students were informed that they could access face-masks from the clinic staff before they recruited patients for TB screening. This orientation session built on the knowledge that was introduced to students in related first-year modules, which covered topics such as TB pathophysiology and epidemiology, infection prevention and control, TB screening and motivational interviewing (MI) techniques.

Once on-site, students were required to conduct about fifteen TB screenings each, using the official tool of the National Department of Health (NDoH) (National Department of Health, 2014) under the supervision of nurses at the PHC facility. As such, students had to recruit and screen people using motivational interviewing (MI) skills based on the TB screening tool to determine their risk of having TB. Pharmacy students then needed to refer all patients with a positive TB screen to the TB room for further investigation and laboratory testing or, if the symptom screen was negative, provide the patient with education on TB preventative measures.

\section{Target population and recruitment}

The target population for the study consisted of two groups, namely second-year pharmacy students and nurses employed at PHC facilities participating in the SLiP programme in the Northern and Tygerberg subdistricts of the Cape Town Metropole during 2017.

The inclusion criteria for the second-year pharmacy students were those who; were registered for the Pharmacology and Clinical Pharmacy (PHC213) module in 2017, participated in SLiP, and provided informed consent to participate in the study. Second-year pharmacy students not registered for PHC213 during 2017 or who did not consent to participate in the study were excluded. Students were informed about the objectives of the research before their SLiP experience. After SLiP, they were invited to participate in the study by signing prior informed consent and completing a self-administered questionnaire.

Nursing staff who were employed at the PHC facilities participating in the SLiP programme (2017) were eligible for participation in this study. Inclusion criteria for the nursing staff at the facility were nurses who interacted directly with the second-year pharmacy students during the time they performed the TB screening at the facility, nursing staff who had interacted with patients that students had referred at the selected facility and those that consented to participate in the study. Nursing staff who did not interact with the students and/or patients referred by students were excluded from the study and those declining to participate. Participant recruitment commenced after the service-learning sessions at the facilities were completed (2017). Facility managers at the participating PHC facilities were contacted telephonically, and appointments were made for the researcher to visit the facilities to provide the nurses with a self-administered questionnaire for them to complete. Participation in this study was voluntary for both cohorts of participants.

\section{Data collection and analysis}

Self-administered semi-structured questionnaires were used to obtain information from students and nursing staff at the health care facilities. These questionnaires were developed by an independent person outside the SLiP programme via the use of the service-learning handbook, which contained the learning objectives and activities. The content of the questionnaires was checked by two experts who designed and implemented the programme over the previous three years to ensure the content validity of the questionnaires. The two questionnaires were also cross-checked and compared to make sure some questions were answered from both perspectives as a form of construct validation. In addition, the students' tuberculosis (TB) screening reports were used to extract objective quantitative information about the details of the screening exercise.

The questionnaires for students and nurses elicited information on demographics, the TB screening process and perceived outcomes of the SLiP programme. The TB screening reports that students had submitted to the SLiP coordinator contained information on the number of patients screened for TB as well as the number of referrals that were sent to the TB nurse for further investigation to confirm a suspect TB infection.

Data collected from the questionnaires were captured into an electronic spreadsheet. The data were checked by six independent research assistants not originally involved in the data capturing to ensure that no errors 
had been made during the data capturing stage. The final data set was then created and exported into SPSS version 22 for descriptive statistical analysis. Due to the descriptive approach to the study with no anticipated inferential analysis to show correlations between variables, all questionnaires were included for the data analysis even though not all participants completed all the questions on the questionnaire. As a consequence, the number of responses per question is given in all Tables reporting the results. In addition, some of the quantitative questions provided respondents with space to write a qualitative statement to qualify their initial response (for example, after a closed-ended question such as: 'Do you think TB screening helped staff at the facility?' Respondents were asked to explain their answer in the following question). These openended responses were coded and thematically analysed, and incorporated into the results' text narrative and not into the Tables.

\section{Results}

One hundred and six ( $n=106)$ second-year pharmacy students conducted their service-learning at nineteen $(n=19)$ health care facilities during 2017. Ninety-nine students from nineteen (19) health care facilities agreed to participate in the study by completing consent forms and questionnaires used for the study. Thirty-eight (38) nurses from fifteen (15) health care facilities agreed to participate in the study. Nurses from two different facilities ( $\mathrm{N}$ and $\mathrm{J}$ ) declined to participate, as they could not recall the aim and objectives of the service-learning programme and the specific activities that students had performed at their respective facilities (2017). For the two remaining facilities ( $F$ and O), no permission was granted to access the facility nurses for research purposes. Table I provides a facilityspecific breakdown of the number of student and nurse participants, the number of patients who were screened by students and subsequently referred to the nurses.

Table I: Number of student and nurse respondents, TB screenings performed and referrals per facility

\begin{tabular}{|c|c|c|c|c|c|}
\hline Facility & $\begin{array}{c}\text { Students' } \\
\text { respondents } \\
\text { Number (\%) }\end{array}$ & $\begin{array}{c}\text { Nurses' } \\
\text { respondents } \\
\text { Number (\%) }\end{array}$ & $\begin{array}{c}\text { Patients } \\
\text { screened } \\
\text { Number (\%) }\end{array}$ & $\begin{array}{c}\text { Average number of } \\
\text { patients screened } \\
\text { per student } \\
\text { Number (\%) }\end{array}$ & $\begin{array}{c}\text { Patients referred to TB } \\
\text { nurse } \\
\text { Number (\%) }\end{array}$ \\
\hline A & $4(4.2 \%)$ & $6(15.8 \%)$ & 60 & 15 & $13(21.7 \%)$ \\
\hline B & $5(5.2 \%)$ & $2(5.3 \%)$ & 90 & 15 & $28(31.1 \%)$ \\
\hline C & $6(6.25 \%)$ & $1(2.6 \%)$ & 75 & 12.5 & $8(10.7 \%)$ \\
\hline D & $5(5.2 \%)$ & $1(2.6 \%)$ & 43 & 14.3 & $0(0 \%)$ \\
\hline $\mathbf{E}$ & $5(5.2 \%)$ & $1(2.6 \%)$ & 45 & 7.5 & $15(33.3 \%)$ \\
\hline $\mathbf{F}$ & $5(5.2 \%)$ & No access granted & 78 & 13 & $3(3.8 \%)$ \\
\hline G & $5(5.2 \%)$ & $1(2.6 \%)$ & 27 & 13.5 & $5(18.5 \%)$ \\
\hline $\mathbf{H}$ & $4(4.2 \%)$ & $2(5.3 \%)$ & 52 & 13 & $25(48.1 \%)$ \\
\hline I & $5(5.2 \%)$ & $4(10.5 \%)$ & 90 & 15 & $4(4.4 \%)$ \\
\hline J & $5(5.2 \%)$ & 0 & 135 & 15 & $4(3.0 \%)$ \\
\hline $\mathbf{K}$ & $4(4.2 \%)$ & $3(7.9 \%)$ & 62 & 15.5 & $4(6.5 \%)$ \\
\hline $\mathbf{L}$ & $2(2.1 \%)$ & $4(10.5 \%)$ & 45 & 15 & $1(2.2 \%)$ \\
\hline $\mathbf{M}$ & $4(4.2 \%)$ & $1(2.6 \%)$ & 32 & 16 & $4(12.5 \%)$ \\
\hline $\mathbf{N}$ & $4(4.2 \%)$ & 0 & 30 & 7.5 & $2(6.7 \%)$ \\
\hline 0 & $5(5.2 \%)$ & No access granted & 90 & 18 & $19(21.1 \%)$ \\
\hline $\mathbf{P}$ & $14(14.1 \%)$ & $1(2.6 \%)$ & 174 & 13.4 & $26(14.9 \%)$ \\
\hline $\mathbf{Q}$ & 3 (3.1\%) & $1(2.6 \%)$ & 58 & 14.5 & $21(36.2 \%)$ \\
\hline $\mathbf{R}$ & $4(4.2 \%)$ & $1(2.6 \%)$ & 48 & 12 & $7(14.6 \%)$ \\
\hline $\mathbf{S}$ & $6(6.1 \%)$ & $9(23.7 \%)$ & 89 & 12.7 & $21(23.6 \%)$ \\
\hline Total & $99(100 \%)$ & $38(100 \%)$ & 1323 & 13.5 & $210(15.9 \%)$ \\
\hline
\end{tabular}

Of the 1323 patients screened by the students, 210 (15.9\%) were referred to the TB nurse for further investigations to confirm a TB diagnosis (Table I). The average number of patients screened per student was recorded to be the highest (18) at Facility $\mathrm{O}$ and lowest (7.5) in Facilities E and N. In addition, referral rates also differed between facilities, with Facility $\mathrm{H}$ recording the highest $(48.1 \%)$ referral rate and Facility $D$ had no referrals.

\section{Participant demographics}

The demographics of study participants are summarised in Table II. Total student participants were 99, and total nurse participants were 38 ; however, not 
all participants completed all the questions, as indicated by the number of responses per question (Table II). The majority of the students were female (62.6\%) and spoke English as their first language (49.5\%). The majority of the nurses $(97.4 \%)$ were female, with more than half (55.3\%) speaking Afrikaans as their first language. Almost three quarters (73.7\%) were professional nurses with more than five years of nursing experience.

Table II: Demographics of participating students $(n=99)$ and nurses $(n=38)$

\begin{tabular}{|c|c|c|}
\hline Demographic indicator & Students & Nurses \\
\hline Gender & $\mathrm{n}=99$ & $\mathrm{n}=38$ \\
\hline - Female & $62(62.6 \%)$ & $37(97.4 \%)$ \\
\hline - Male & $37(37.4 \%)$ & $1(2.6 \%)$ \\
\hline First language & $n=97$ & $\mathrm{n}=37$ \\
\hline - Afrikaans & $8(8.2 \%)$ & $21(55.3 \%)$ \\
\hline - English & $48(49.5 \%)$ & $8(21.1 \%)$ \\
\hline - $\quad$ isiXhosa & $21(21.6 \%)$ & $8(21.8 \%)$ \\
\hline - Others & $20(20.6 \%)$ & $1(2.6 \%)$ \\
\hline Job title & - & $n=38$ \\
\hline - Professional nurse & - & $28(73.7 \%)$ \\
\hline - Clinical nurse practitioner & - & $4(10.5 \%)$ \\
\hline - Enrolled nursing assistant & - & $4(10.5 \%)$ \\
\hline - $\quad$ Mental health practitioner & - & $1(2.6 \%)$ \\
\hline - Staff nurse & - & $1(2.6 \%)$ \\
\hline Years of practice & - & $\mathrm{n}=38$ \\
\hline - 1 to 2 years & - & $5(13.2 \%)$ \\
\hline - 3 to 5 years & - & $8(21.1 \%)$ \\
\hline - More than 5 years & - & $25(65.8 \%)$ \\
\hline Role at facility & - & $n=38$ \\
\hline - Facility manager & - & $2(5.3 \%)$ \\
\hline - $\quad$ TB nurse & - & $17(44.7 \%)$ \\
\hline - Other & - & $19(50 \%)$ \\
\hline Interaction with students & - & $n=33$ \\
\hline - Orientation prior to TB screening & - & 19 (50\%) \\
\hline - $\quad$ Received patient referrals from students & - & $10(26.3 \%)$ \\
\hline - General assistance & - & $4(10.5 \%)$ \\
\hline
\end{tabular}

\section{Perceptions of implementation of TB screening activities}

The student-led screening process was split into two stages, namely recruitment and screening. Recruitment entailed students approaching patients to invite them to participate in the screening process. Screening referred to the part of the process where students administered the TB suspect screening tool to the patient who had consented to participate.

Table III below shows the students and nurses' responses regarding recruitment and screening locations, students' experiences of recruitment and screening of patients, and communication with patients and nurses. Students were at liberty to give more than one answer to questions about recruitment and screening locations. Most students recruited patients from the general waiting room $(n=89)$ and TB waiting room $(n=25)$ and proceeded to screen patients in the general waiting room $(n=69)$, the TB waiting room ( $n=21)$, and private consulting rooms $(n=26)$. Most students recruited and screened patients in the same healthcare facility location, while fewer students $(n=26)$ recruited and screened patients in different locations (e.g. recruited in the waiting room and screened in a private consultation room).

In comparison, nurses mostly reported students recruiting patients from the general waiting room $(n=27)$ and TB waiting room ( $n=22)$. More than two-thirds (70.8\%) of the nurses believed that the general waiting room was appropriate for recruiting patients for TB screening. In contrast to students, the majority of nurses believed students screened patients in private consultation rooms $(n=16)$ and the TB waiting room $(n=12)$.

Table III reports whether students found it easy or difficult to recruit and screen patients for TB. Almost half of the students $(46.5 \%)$ agreed that it was easy to recruit patients, and two-thirds (68.7\%) indicated that it was easy to screen these patients for TB. Students who indicated that recruitment of patients was easy felt that patients showed a willingness to get screened for TB and felt supported by nurses at the facility. Students who felt neutral about the recruitment process indicated that they "felt awkward approaching patients", "lacked the courage to approach patients for screening", "experienced a 
language barrier", indicated some clinics were "too full of patients" or "totally empty", and reported that some patients were "reluctant to be screened for TB" or "impatient to undergo TB screening". Students who found the recruitment process difficult indicated that there was "no privacy to communicate effectively with patients" and that "most of the patients were disinterested in the TB screening exercise".

Half of the nurses (50\%) believed students found it easy to recruit patients for TB screening, which correlated with the students' opinion (46.5\%). Almost half of the students (49\%) found it easy to communicate with patients, and two-thirds (68.7\%) found it easy to communicate with the nursing staff.

Table III: Recruitment and screening of patients process

\begin{tabular}{|c|c|c|}
\hline & $\begin{array}{c}\text { Student } \\
\text { responses } \\
\text { Number (\%) }\end{array}$ & $\begin{array}{c}\text { Nurses } \\
\text { response } \\
\text { Number (\%) }\end{array}$ \\
\hline Recruitment location* & $\mathrm{n}=121$ & $n=54$ \\
\hline - General waiting room & 89 & 27 \\
\hline • TB waiting room & 25 & 22 \\
\hline - Other & 7 & 5 \\
\hline TB screening location* & $n=144$ & $n=50$ \\
\hline - General waiting room & 69 & 6 \\
\hline - TB waiting room & 21 & 12 \\
\hline $\begin{array}{l}\text { - Private consultation } \\
\text { room }\end{array}$ & 26 & 16 \\
\hline - Other & 28 & 16 \\
\hline $\begin{array}{l}\text { Recruitment of patients } \\
\text { were: }\end{array}$ & $\mathrm{n}=99$ & $n=36$ \\
\hline - Easy & $46(46.5 \%)$ & $18(50 \%)$ \\
\hline - Neutral & $28(28.3 \%)$ & $11(30.5 \%)$ \\
\hline - Difficult & $25(25.3 \%)$ & $7(19.4 \%)$ \\
\hline Screening of patients were: & $n=96$ & \\
\hline - Easy & $66(68.7 \%)$ & - \\
\hline - Neutral & $18(18.8 \%)$ & - \\
\hline - Difficult & $12(12.5 \%)$ & - \\
\hline $\begin{array}{l}\text { Communication with } \\
\text { patients were: }\end{array}$ & $n=98$ & \\
\hline - Easy & 48 (49\%) & - \\
\hline - Neutral & $33(33.7 \%)$ & - \\
\hline - Difficult & $17(17.4 \%)$ & - \\
\hline $\begin{array}{l}\text { Communication with } \\
\text { nurses were: }\end{array}$ & $n=99$ & \\
\hline - Easy & $69(69.7 \%)$ & - \\
\hline - Neutral & $8(8.1 \%)$ & - \\
\hline - Difficult & $22(22.2 \%)$ & - \\
\hline
\end{tabular}

\section{Perceived outcomes of the SLiP programme}

The last part of the questionnaires inquired about students' and nurses' thoughts on the outcomes (if any) of students' TB screening efforts as it related to patients, the health facility staff and student learning (Table IV). Students were evenly divided regarding whether their TB screening helped staff at the facility ( $n=99)$, with about a third agreeing (38.4\%), a third disagreeing (32.3\%) and another third (29.3\%) being unsure. Students who believed the TB screening helped the nursing staff explained that their TB screening seemed to have 'lessened the nurses' workload as it replaced some of the TB screening which the nurses would have done and others felt that nurses had too little time to conduct TB screening as part of their daily activities. Students who were unsure whether their TB screening efforts helped facility staff reported that some clinics already performed TB screening with or without their help, some of the patients screened were already on TB treatment and one student was unsure if the patients he had referred received the required care from the nurse. Students who reported that their screening did not help the facility mentioned that it helped the students and patients more than staff, was unsure if a referred patient got attended to or not, did not refer any patients to nurse, and that one facility had very few patients in attendance.

Table IV: Student and nurse responses on perceived outcomes of the TB screening outcomes on patients, nurses and student learning.

\begin{tabular}{|c|c|c|}
\hline & $\begin{array}{c}\text { Students' } \\
\text { response } \\
\text { Number (\%) }\end{array}$ & $\begin{array}{c}\text { Nurses' } \\
\text { response } \\
\text { Number (\%) } \\
\end{array}$ \\
\hline TB screening helped staff & $\mathrm{n}=99$ & \\
\hline - Yes & 39 (38.4\%) & - \\
\hline - No & $31(32.3 \%)$ & - \\
\hline - Maybe & $29(29.3 \%)$ & - \\
\hline $\begin{array}{l}\text { TB screening helped } \\
\text { patients }\end{array}$ & $n=98$ & $n=9$ \\
\hline - Yes & $59(60.2 \%)$ & $4(44.4 \%)$ \\
\hline - No & $8(8.2 \%)$ & $2(22.2 \%)$ \\
\hline - Maybe & $31(32.7 \%)$ & $3(33.3 \%)$ \\
\hline $\begin{array}{l}\text { TB screening increased } \\
\text { students' learning }\end{array}$ & $n=96$ & $n=20$ \\
\hline - Yes & 75 (78.1\%) & $16(48.5 \%)$ \\
\hline - No & $10(10.4 \%)$ & - \\
\hline - Maybe & $11(11.5 \%)$ & $4(12.1 \%)$ \\
\hline $\begin{array}{l}\text { Students' training } \\
\text { adequate for TB } \\
\text { screening }\end{array}$ & $n=93$ & $n=23$ \\
\hline - Yes & 59 (63.4\%) & $14(60.9 \%)$ \\
\hline - No & $17(18.3 \%)$ & $3(13 \%)$ \\
\hline - Maybe & $17(18.3 \%)$ & $6(26.1 \%)$ \\
\hline
\end{tabular}

Most students (60.2\%) thought the TB screening benefitted patients at the facility, because they learnt more about TB from the students in addition to being screened. On the other hand, a minority of students (8.2\%) reported that their TB screening did not benefit 
patients. Their reasons included that some patients already had knowledge about TB and were uncooperative or already screened by a nurse, one facility was empty, and one student complained about a language barrier.

Most students (78\%) reported that the TB screening done at the facilities was a valuable learning experience for them (Table IV). They gained more clinical experience, improved their communication skills, and acquired more knowledge about TB. A minority of students (10.4\%) reported that they learned nothing from the TB screening exercise because they were uncomfortable with patients, did not refer any patients to the nurse, lacked conversational skills, received no help from nursing staff, and felt that patients were frustrated with the screening process.

The majority (63.4\%) of students believed they were adequately trained to conduct TB screening at the facilities. Similarly, most nurses $(60.9 \%)$ believed students were well prepared for the TB screening of patients. In terms of student learning, about half of the nurse respondents (48.5\%) believed the TB screening exercise had an impact on the students in terms of more knowledge about TB, 39.4\% of nurses believed students gained more clinical experience, and $12.1 \%$ of the nurses were unsure of the impact of the TB screening on student learning.

In order to improve the service-learning programme and maximise its benefits to both students and the facility, nurses recommended that in addition to the TB screening, students could deliver health talks to patients, conduct TB outreaches in the surrounding communities, support tasks in the pharmacy, observe procedures in the clinics, conduct TB tests and interpret results, and conduct cardiovascular disease and diabetes screenings. About a fifth (18.4\%) of the nurses noted that students generally required more interactions with patients. In terms of logistics, one nurse advised that the SLiP clinical hours be extended, and another suggested the day be changed from Fridays to Mondays when more patients were in attendance at that facility.

\section{Discussion}

This research aimed to assess the implementation of the TB screening of the second year service learning in the pharmacy programme, based on the perceptions of the participating students and nurses and reviewing students' TB screening reports. Of the 106 students registered for PHC213 (2017), 99 students chose to participate in this study, giving a response rate of $93 \%$. Such high participation figures offered an adequate representation of the views of the students in the class across the PHC facilities that participated in the servicelearning programme (2017). A total of thirty-eight (38) nurses employed at 15 facilities participated in the study. Facility participation rates ranged between 0 and 9 participants per facility, which implied an under/overrepresentation of some facilities. This might limit the correlation between the student and nurse responses to the same questions.

This discussion will first present the principle study findings separated into three sub-headings: the overall implementation of the TB screening service-learning programme, the interprofessional engagement between the students and nurses, and student-patient interactions. Secondly, the research implications will be discussed, which will aim to synthesise implications for education, practice and policy in both the global and South African context.

\section{Principle study findings}

Implementation of TB screening by pharmacy students at PHC facilities

In terms of preparation for the service-learning activity, the majority $(63.4 \%)$ of students believed they were adequately trained to conduct TB screening at the facilities and, similarly, most of the nurses agreed that students were well prepared. The combined approach of a focused activity (TB screening) and preparing students on campus prior to clinical application in this study seemed to offset literature on introductory pharmacy practice experiences where on-site preceptors raised concerns about inadequate knowledge of junior students (Gibson et al., 2017; Stanton et al., 2017).

The majority of students $(68.7 \%)$ reported that screening patients were easy. This agrees with research investigating preceptors' experience of introductory pharmacy practice experiences that reported that junior students "had the ability" and "should be involved in patient care" (Gibson et al., 2017, p. 4). Indeed, the average number of patients screened per student was between 13 and 14, which worked out to $90 \%$ of the initial target (15 patients per student) required from students for their service activity. Although promising, this average number did show some inter-facility variation with a maximum of 18 and a minimum of 7.5 patients screened between facilities.

Similarly, the referral rates between facilities showed marked variation with a maximum of $48.1 \%$ versus $0 \%$ of patients referred for further investigations. Based on an ad hoc sub-analysis at the facility level (see Appendix A), it is difficult to interrogate this finding from the 
current research data. In terms of the study data, the only related variable that might explain this phenomenon would be the location of recruitment, i.e. the general waiting room versus the TB waiting room. A logical conclusion would be that fewer people with active TB symptoms would be found in the general waiting room because patients with any complaint will be seated here. In contrast, people in the TB waiting room would have symptoms of active TB. A logical assumption would then be that a higher number of referrals would be expected from recruitment in the TB waiting room. However, as per the descriptive trends depicted by Table A, the referral rate does not show a consistent difference between the two locations. Another consideration that falls beyond the study data is the TB incidence/prevalence in the clinic catchment area. However, TB incidence/prevalence rates are not available per clinic catchment area, so it is difficult to link the two without specific data.

An obvious problem relating to the quarter of students who recruited and screened patients from the TB waiting room was their potential direct exposure to TB. Literature on undergraduate medical students in Cape Town showed a high risk of occupationally acquired TB, with an unmet need for comprehensive occupational health services and support (van der Westhuizen \& Dramowski, 2017). Therefore, the initial on-campus orientation for students as described earlier, which speaks to patient recruitment location and student prior knowledge of infection prevention and control, is an important consideration for future student placement and programme follow up.

In addition, structural limitations were noted for the screening as the vast majority of students reported that they recruited and screened people in the general waiting room. This could pose problems because TB is a stigmatised disease (Daftary et al., 2017b), and many people might not be forthcoming in discussing their TB history and symptoms without privacy. This finding resonates with nurse respondents who although indicating that the general waiting room was appropriate to recruit patients, many of them assumed patients were screened in a private consultation room (which was not accurate in the end).

In terms of student learning, both nurse and student participants believed the TB screening activity improved students' knowledge about TB, provided more clinical experience, and improved their communication skills. Similarly, McKennon and Arnold (2016) from the University of Washington (USA) found a significant improvement in pharmacy students' knowledge of TB after conducting a practical course on TB screening. More generally, the literature agrees that medical students' confidence in performing clinical tasks increased over the course of their clinical training, and this was unrelated to the location of the clinical placements (McNair et al., 2016). In addition, the development of communication skills has also been noted in the literature investigating introductory pharmacy practice experiences for first-year students (Stanton et al., 2017).

\section{Interaction between students and nurses (interprofessional experience)}

The second objective of the service-learning programme required students to interact with nurses as the interprofessional experience would enable them to appreciate the nurse-driven PHC system in South Africa (Coovadia et al., 2009). Over two-thirds (69.7\%) of the students found it was easy to communicate with the nursing staff, which aligns with literature that suggested an easy flow of communication between pharmacists/ pharmacy students and nurses promotes a synergistic relationship between all those who contribute to a patient's well-being (Hudson \& Croker, 2018). This study adds to the dearth of evidence reporting on nurses' supervision of pharmacy students in an experiential learning environment. Literature on medical students either working alongside or shadowing nurses has shown enhanced competencies of collaboration, communication and professionalism in addition to enhanced respect for the nursing profession (Jain et al., 2012; Butterworth et al., 2018).

However, findings also indicate limited interactions between students and nursing staff, as illustrated by the lack of alignment of responses between the nurses and the students regarding screening location. Indeed, most nurse respondents reported orientating the students, and at two facilities, the nursing staff had declined to participate because they could not recall students at their facilities. This disparity is further reflected in the division among the students' opinions as to whether their activities were helpful, neutral or hindering for nursing staff at the health care facilities. Their perceptions could be extrapolated as to how much students felt that they were being incorporated into and contributing towards the health care provider team's service delivery efforts at the facility. The group that believed they helped through their TB screening thought that they saved the nurses' time because they would not need to screen these patients for TB.

Yet almost two-thirds of student respondents (61.6\%) in this study were either unsure or did not think they contributed to a team effort in TB screening at the facility. These respondents did not know whether the patients got to the nurses and were helped or thought they were duplicating what was already being done at the facility. The latter could be linked with the fact that 
many students recruited and screened patients in the TB waiting room. Indeed, South African literature reiterates that the focus in $\mathrm{PHC}$ facilities of primarily screening patients presenting with TB symptoms at the TB clinic overlooks the screening of patients presenting to the facility for other health-seeking reasons (Claasens et al., 2013; Chihota et al., 2015; Kweza et al., 2018).

The seemingly poor incorporation of pharmacy students into the health care team at some facilities might be related to the current lack of interprofessional contact between nurses and pharmacists in the South African PHC setting (Gray et al., 2016). Indeed, almost three-quarters of nurse respondents $(65.8 \%)$ had more than five years of nursing experience running a vertical TB programme and have witnessed pharmacists not routinely being involved in TB care apart from medicine supply. It was thus not surprising that some nurses recommended that pharmacy students help out in the pharmacy. Similarly, inter-professional impressions among undergraduate nursing and pharmacy students from the Middle East showed a basic understanding of one another's roles but tended to closely follow traditional scripts (Wilbur and Kelly, 2015). Yet, in China, pharmacy and nursing students showed somewhat positive attitudes towards nurse-pharmacist collaboration in the first and second years of study (Wang et al., 2018).

\section{Patient interaction}

The TB screening activity was second-year students' first exposure to a public sector PHC facility, where the learning activity required self-initiated patient interaction that involved a socially stigmatised disease. Not surprisingly, students found it easier to communicate with nurses than patients. They also noted that recruiting patients for TB screening was more difficult than the actual screening procedure. This difficulty seemed to be intuitive as, after getting over the initial awkwardness of initiating a conversation, identifying and managing language barriers, and establishing some level of trust, the students would find it much easier to screen such patients for TB. In a relatively similar vein, Pitkala and Manteranta (2014) found that medical students from the University of Helsinki experienced emotions such as anxiety, helplessness and confusion during their first patient experiences in a clinic setting (Pitkala \& Manteranta, 2014). In addition, Littlewood and colleagues (2005) found that early practical experience strengthens health professional students' learning and confidence to meet and interview patients (Littlewood et al., 2005).
The language barrier encountered by some students was expected in the South African setting, which boasts 11 official languages. The language distribution in the Western Cape Province from a 2016 survey showed that Afrikaans (46.6\%), isiXhosa (31.1\%) and English (19.6\%) accounted for the majority of languages spoken by the population (Statistics South Africa, 2018). Half (49.5\%) of the students indicated English as their first language. A study by Clark and colleagues (2015), which evaluated the experiences of medical and pharmacy students of the University of Saskatchewan in Western Canada at their community service programme, revealed that students found the language barrier to be one of the factors that might impede good health of the community. Also, a study by Naidoo (2014) revealed that in South Africa, language barriers compromise a large proportion of the population in their access to health care services and quality care.

In addition to the barrier reported by some students in this study, most students found the TB screening easy and thought it was beneficial to patients (63.4\%). Similarly, literature from a Canadian pharmacy school showed how pharmacy students could improve patient care by participating in experiential learning at a patient care clinic located in the pharmacy school (Jorgenson et al., 2016).

\section{Implications for pharmacy education, practice and policy}

The relatively successful implementation of this interprofessional early experience educational programme that is patient-centred and focused on a primary care prevention activity aligns with needsbased education as advocated by the International Pharmaceutical Federation (FIP). This approach aims to "systematically link practice competencies to patient and population health needs" (Anderson et al., 2011). In particular, it is aligned with the South African government's drive to revitalise preventive care in the health system serves as a clarion call for pharmacy education institutions to embed community-oriented service-learning pedagogy into academic programmes to strengthen graduate competencies beyond discipline-based learning and skills development (Bheekie \& Bradley, 2016).

In following a needs-based approach, this educational activity highlighted two rather unique vantage points embedded in traditional health education and practice stereotypes. The first point was that the servicelearning programme occurred outside the pharmacy, with nurses supervising pharmacy students, instead of a pharmacist, thereby challenging the position and role of the pharmacist in PHC facilities, as most PHC facilities in South Africa neither operate with an on-site 
pharmacist nor offer services from a formal pharmacy (Bobbins et al., 2020). It is the hope of the School that the development and expansion of this programme may add to the normalisation of the presence of pharmacists in public primary health care clinics beyond the pharmacy in a patient-centred role (as opposed to a product centred one) that overlaps and compliments that of the nurse in primary health care. As such, interprofessional collaboration is realised as a competency standard as per the South African Pharmacy Council (South African Pharmacy Council, 2017).

In addition, the novelty of this clinical skills development context contrasts with those in developed countries where student-led screening programmes are primarily pharmacy-based (Raney, 2013). While education in the health sciences traditionally focused on hospital ward-based clinical skills development (Frenk et al., 2010), primary care level clinic-based skills development in pharmacy training remained peripheral.

The link between a needs-based education and practice competencies may blur the boundaries between education and practice. Indeed, policy documents directed at pharmacy practice published by the WHO and FIP agree that pharmacists are often the first-time contact for people with symptoms of TB and can participate as a vital link in national TB control programme efforts, scaling up public-private mix approaches and promoting rational use of anti-TB medicines (International Pharmaceutical Federation \& World Health Organization, 2011). Tasks essential for quality TB care, such as early identification of TB suspects and referral for diagnosis as well as providing educational information and support to patients living with TB in the community, thereby enhancing treatment success, reducing defaults and contributing to cutting the disease transmission (International Pharmaceutical Federation \& World Health Organization, 2011; Mkele, 2010).

Through the competencies imparted and confidence that students acquire through participating in this programme, it is hoped that TB screening would become second nature, even in a traditional pharmacy setting. TB control programmes, especially in low- and middle-income countries, require early case detection, referral for testing, diagnosis and timeous initiation of TB treatment. Privately-owned community pharmacies which are easily accessible to communities serve as a key resource in improving case detection, but they have been under-utilised in TB control programmes (Miller \& Goodman, 2020). In India, a mixed-methods study piloted over 18 months in 108 pharmacies employed a novel TB screening and referral intervention integrated into a public-private mix (PPM) programme, resulting in 1674 referrals and 255 cases of TB that were diagnosed (Daftary et al., 2019). Therefore, expanding the role of South African community pharmacists would require training in line with the national TB control programme to ensure the provision of quality TB care, where collaboration among multiple stakeholders (WHO, FIP, STOP TB, regulatory authorities, ministries of health, pharmacy associations and training institutions) would be a cornerstone in establishing pharmacy-specific guidelines (Miller \& Goodman, 2020). Such an expanded role for community pharmacists would form an inextricable link in strengthening TB case detection and referral to public sector facilities for further management at the primary care level.

\section{Limitations}

The results of this study are primarily based on selfreport by pharmacy students and nurses, and therefore are not entirely objective to describe the actual interactions between students and nurses. Additionally, in terms of nurse respondents, some facilities were over and underrepresented, and this limited the comparability of the students and nurses responses. Furthermore, the nurses that did respond tended to complete their questionnaires briefly and without contextualising details. Patients' views about the TB screenings conducted on them by the students were not documented, and it is unclear if using motivational interviewing was useful to students and patients. In addition, patients who were referred to the nurses were not followed up to either confirm testing or diagnosis.

\section{Conclusion}

This study provides preliminary findings on the successful implementation of student-led TB screening offered by second students under the supervision of nurses in PHC facilities. It also revealed limitations in terms of a lack of privacy for screening and possible unnecessary exposure to TB by students recruiting patients from the TB waiting room. In addition, it raised questions about the current untapped role of the pharmacist in TB prevention and control at the PHC level.

The research has highlighted numerous areas in which the programme can be improved, including providing students with more physical resources to do the screening at facilities, strengthening the partnership with nurses by hosting workshops, and possibly preparing students more rigorously in the self-initiated engagement aspect of the patient interaction. Further 
research to monitor and evaluate the programme should consider face to face interviews or focus groups when eliciting feedback from nurses (as opposed to the self-administered questionnaires used in this study), independent observations at facilities to provide objective evidence for evaluation, and a longitudinal programme evaluation to establish an evidence-base to guide programme improvement.

\section{Declarations of interest}

The authors report no conflicts of interest. The authors alone are responsible for the content and writing of the article.

\section{Acknowledgements}

The authors would like to thank the various clinic managers and nurses who facilitated the data collection process at facilities. The fourth-year pharmacy students (Megan April, Qaanitha Dramat, Nchabeleng Mologadi, Jayed Oliver, Rushda Salie, and Najma Yusuf) who helped capture data from the questionnaires into Excel sheets. Marissa Orffer van Zyl who helped with the administrative processes, and the School of Pharmacy who provided the platform for this research. This research was funded by the National Research Foundation of South Africa, grant numbers; CE 14061870029 (2017) and CEC 180513328650 (2019).

\section{References}

Anderson, C., Brock, T., Bates, I., Rouse, M., Marriott, J., Manasse H., Futter, B., Bhojra, S., Brown, A. \& Gal, D. (2011). Transforming health professional education. American Journal of Pharmaceutical Education, 75(2), 22. https://doi.org/10.5688/ajpe75222

Bheekie, A., \& Bradley, H. (2016). Re-engineering of South Africa's primary health care system: where is the pharmacist?. South African Family Practice, 58(6), 242-248

Bobbins, A. C., Burton, S., \& Fogarty, T. L. (2020). Different models of pharmaceutical services and care in primary healthcare clinics in the Eastern Cape, South Africa: Challenges and opportunities for pharmacy practice. African Journal of Primary Health Care \& Family Medicine, 12(1). https://doi.org/10.4102/phcfm.v12i1.2323

Butterworth, K., Rajupadhya, R., Gongal, R., Manca, T., Ross, S., \& Nichols, D. (2018). A clinical nursing rotation transforms medical students' interprofessional attitudes. Plos one, 13(5). https://doi.org/10.1371/journal.pone.0197161
Calligaro, G.L., Zijenah, L.S., Peter, J.G., Theown, G., Buse, V., McNerney, R., Bara, W., Bandanson, T., Govender, U., Tomasicchio, M., Smith, L., Mayosi, B.M., \& Dheda, K. (2017). Effect of new tuberculosis diagnostic technologies on community based intensified case finding: a multicentre randomised controlled trial. The Lancet, Infectious Disease, 17 (4), 441-450. https://doi.org/10.1016/S14733099(16)30384-X

Chihota, V. N., Ginindza, S., McCarthy, K., Grant, A. D., Churchyard, G., \& Fielding, K. (2015). Missed opportunities for TB investigation in primary care clinics in South Africa: experience from the XTEND trial. PLoS One, 10(9). https://doi.org/10.1371/journal.pone.0138149

Churchyard, G. J., Mametja, L. D., Mvusi, L., Ndjek, N., Hesseling, A. C., Reid, A., \& Babatunde, S. (2014). Tuberculosis control in South Africa: Successes, challenges and recommendations. South African Medical Journal, 104(3), 244-248. https://doi.org/10.7196/SAMJ.7689

Colvin, C., Mugyabuso, J., Munuo, G., Lyimo, J., Oren, E., Mkomwa, Z., ... \& Mueller, L. (2014). Evaluation of community-based interventions to improve TB case detection in a rural district of Tanzania. Global Health: Science and Practice, 2(2), 219-225. https://doi.org/10.9745/GHSP-D-14-00026

Coovadia, H., Jewkes, R., Barron, P., Sanders, D., \& Mclntyre, D. (2009). The health and health system of South Africa: historical roots of current public health challenges. The Lancet, 374(9692), 817-834. https://doi.org/10.1016/S01406736(09)60951-X

Claassens, M. M., Jacobs, E., Cyster, E., Jennings, K., James, A., Dunbar, R., ... \& Beyers, N. (2013). Tuberculosis cases missed in PHC facilities: should we redefine case finding?. The International journal of tuberculosis and lung disease, 17(5), 608-614. https://doi.org/10.5588/ijtld.12.0506

Claassens, M. M., Van Schalkwyk, C., Dunbar, R., Ayles, H., \& Beyers, N. (2016). Patient diagnostic rate as indicator of tuberculosis case detection, South Africa. Emerging $\begin{array}{lll}\text { infectious } & \text { diseases, } & \end{array}$ https://doi.org/10.3201/eid2203.151618

Clark M., McKague M., McKay S., Ramsden V. (2015). Deeper learning through service: Evaluation of an interprofessional community service-learning program for pharmacy and medical students. Journal of Research in Interprofessional Practice and Education, 5 (1), 3-25. https://doi.org/10.22230/jripe.2015v5n1a175

Daftary, A., Jha, N., \& Pai, M. (2017a). Enhancing the role of pharmacists in the cascade of tuberculosis care. Journal of epidemiology and global health, 7(1), 1-4. https://doi.org/10.1016/j.jegh.2016.05.001

Daftary, A., Frick, M., Venkatesan, N., \& Pai, M. (2017b). Fighting TB stigma: we need to apply lessons learnt from HIV activism. Journal of Clinical Pathology, 2 (4), 1-4. https://doi.org/10.1136/bmjgh-2017-000515

Daftary, A., Satyanarayana, S., Jha, N., Singh, M., Mondal, S., Vadnais, C., \& Pai, M. (2019). Can community pharmacists improve tuberculosis case finding? A mixed methods intervention study in India. BMJ global health, 4(3), e001417. https://doi.org/10.1136/bmjgh-2019-001417 
Frenk, J., Chen L., Butta, Z.A., Cohen, J., Crisp, N., Evans, T., Fineberg, H., et al. (2010). Health professionals for a new century: transforming education to strengthen health systems in an interdependent world. The Lancet, 376(9756): 1923-1958. https://doi.org/10.1016/S0140-6736(10)61854-5

Gibson, M. J., Sullivan, D., Tubbs, C., Mirtallo, J., \& Kelley, K. (2016). Assessment of barriers to providing Introductory Pharmacy Practice Experiences (IPPEs) in the hospital setting. INNOVATIONS in pharmacy, 7(2). https://doi.org/10.24926/iip.v7i2.442

Gray, A., Riddin, J., \& Jugathpal, J. (2016). Health care and pharmacy practice in South Africa. The Canadian journal of $\begin{array}{lll}\text { hospital pharmacy, } & 69(1), & \end{array}$ https://doi.org/10.4212/cjhp.v69i1.1521

Hudson, J.N., \& Croker, A. (2018). Educating for collaborative practice: an interpretation of current achievement and thoughts for future directions. Medical Education, 52 (1), 114-124. https://doi.org/10.1111/medu.13455

International Pharmaceutical Federation \& World Health Organisation joint statement (2011). The role of pharmacists in tuberculosis care and control. Hyderabad, India. Available at: https://www.who.int/tb/features archive/who fip joint stateme $\underline{\text { nt.pdf }}$

Jain, A., Luo, E., Yang, J., Purkiss, J., \& White, C. (2012). Implementing a nurse-shadowing program for first-year medical students to improve interprofessional collaborations on health care teams. Academic Medicine, 87(9), 1292-1295. https://doi.org/10.1097/ACM.0b013e31826216d0

Jorgenson, D. J., Landry, E. J., \& Lysak, K. J. (2016). A mixed methods evaluation of a patient care clinic located within a pharmacy school. International journal of clinical pharmacy, 38(4), 924-930. https://doi.org/10.1007/s11096-016-0313-6

Kweza, P. F., Van Schalkwyk, C., Abraham, N., Uys, M., Claassens, M. M., \& Medina-Marino, A. (2018). Estimating the magnitude of pulmonary tuberculosis patients missed by primary health care clinics in South Africa. The International Journal of Tuberculosis and Lung Disease, 22(3), 264-272. https://doi.org/10.5588/ijtld.17.0491

Littlewood, S., Ypinazar, V., Margolis, S., Scherpbier, A., Spencer, J. \& Dorman, T. (2005). Early practical experience and the social responsiveness and clinical education: systematic review. BMJ 331, 387-391. https://doi.org/10.1136/bmj.331.7513.387

McCreesh, N., Faghmous, E., Looker, C., Dodd, P.J., Plumb, I.D., Shanaube, K., Muyoyeta, M., Godfrey-Fausset, P., Ayles, H. \& White R.G. (2016). Coverage of clinic-based TB screening in South Africa may be low in risk groups. Public Health Action, 6(1), 19-21. https://doi.org/10.5588/pha.15.0064

McKennon, S.A. \& Arnold, J. (2016). Student pharmacists as tuberculosis screeners. American Journal of Pharmaceutical Education, 80 (2), 24. https://doi.org/10.5688/ajpe80224

McNair, R., Griffiths, L., Reid, K. \& Sloan, H. (2016). Medical students developing confidence and patient centeredness in diverse clinical settings: a longitudinal survey study. BMCMedical Education, 16 (1), 176. https://doi.org/10.1186/s12909-016-0689-y

Miller, R., \& Goodman, C. (2020). Quality of tuberculosis care by pharmacies in low-and middle-income countries: Gaps and opportunities. Journal of Clinical Tuberculosis and Other
Mycobacterial
Diseases,
18 ,
https://doi.org/10.1016/j.jctube.2019.100135

Mkele, G. (2010). The role of the pharmacist in TB management. SA Pharmaceutical Journal, 77(2), 18-20

Naidoo, S. (2014). Transcultural and language barriers to patient care. South African Dental Journal, 69(9), 425-426

National Department of Health. (2014). National Tuberculosis Management Guidelines 2014. Available at: http://www.tbonline.info/media/uploads/documents/ntcp_ adult_tb-guidelines-27.5.2014.pdf

Pitkala, K.H \& Mantyranta, T. (2004). Feelings related to first patient experiences in medical school: a qualitative study on students' personal portfolios. Patient Education and Counselling, 54(2), 171-177. https://doi.org/10.1016/S07383991(03)00209-X

Raney, E. C. (2013). An elective course on pharmacy-based health screenings. American Journal of Pharmaceutical Education, 77(6). https://doi.org/10.5688/ajpe776131

Rutter L. (2018). Red alert on TB infection control in clinics. Available at: http://tac.org.za/news/tb-infection-controlfalls-short-many-clinics-tac-survey/

South African Pharmacy Council. (2017). Competency Standards for Pharmacists in South Africa, Pretoria, South Africa. Available at: https://www.mm3admin.co.za/documents/docmanager/0C43CA52121E-4F58-B8F6-81F656F2FD17/00126360.pdf

Stanton, R. B., Kimble, C., Butt, M. T., Anderson, S. L., BroedelZaugg, K., \& Anderson Jr, H. G. (2017). The opinion of preceptors and students of very early IPPE rotations delivered concurrently with didactic courses. Currents in Pharmacy Teaching and Learning, 9(1), 55-59. https://doi.org/10.1016/j.cptl.2016.08.049

Statistics South Africa. (2018). Provincial profile: Western Cape, Community Survey 2016, Report 03-01-07.

van der Westhuizen, H., \& Dramowski, A. (2017). When students become patients: TB disease among medical undergraduates in Cape Town, South Africa. South African Medical Journal, 107(6), 475-479. https://doi.org/10.7196/SAMJ.2017.v107i6.12260

van Huyssteen, M., \& Bheekie, A. (2015) Service-learning in Pharmacy: evaluating opportunities toward social accountability. In Lan Lin P, Wiegand MR \& Smith-Tolken AR (Eds.), Service-Learning in Higher Education: Building Community Across the Globe. University of Indianapolis Press, Indianapolis, USA

Wang, S. P., Wang, J., Huang, Q. H., Zhang, Y. H., \& Liu, J. (2018). Pharmacy and nursing students' attitudes toward nursepharmacist collaboration at a Chinese university. BMC medical education, 18(1), 179. https://doi.org/10.1186/s12909-018-12850

Wilbur, K., \& Kelly, I. (2015). Interprofessional impressions among nursing and pharmacy students: a qualitative study to inform interprofessional education initiatives. BMCMedical Education, 15 (53), 1-8. https://doi.org/10.1186/s12909-015-0337-y

World Health Organization. (2019). Global Tuberculosis Report. Available at: https://www.who.int/tb/publications/globalreport/en/ 
Appendix A: Facility level analysis for the location of patient recruitment as reported by students

\begin{tabular}{|c|c|c|c|c|c|c|}
\hline Facility & $\begin{array}{l}\text { Number of } \\
\text { students who } \\
\text { completed the } \\
\text { questionnaire }\end{array}$ & $\begin{array}{l}\text { Number of } \\
\text { students } \\
\text { recruiting } \\
\text { patients from the } \\
\text { general waiting } \\
\text { room }\end{array}$ & $\begin{array}{l}\text { Number of students } \\
\text { recruiting patients } \\
\text { from TB waiting } \\
\text { room }\end{array}$ & $\begin{array}{l}\text { Number of } \\
\text { patients } \\
\text { screened by } \\
\text { students }\end{array}$ & $\begin{array}{l}\text { Average } \\
\text { number of } \\
\text { patients } \\
\text { screened per } \\
\text { student }\end{array}$ & $\begin{array}{l}\text { No of patients } \\
\text { referred to TB } \\
\text { nurse (\%) }\end{array}$ \\
\hline A & $4^{*}$ & 4 & 4 & 60 & 15 & $13(21.7 \%)$ \\
\hline B & 3 & 3 & 0 & 90 & 15 & $28(31.1 \%)$ \\
\hline C & 5 & 5 & 0 & 75 & 12.5 & $8(10.7 \%)$ \\
\hline D & 5 & 4 & 1 & 43 & 14.3 & $0(0 \%)$ \\
\hline$E$ & $5^{*}$ & 2 & 5 & 45 & 7.5 & $15(33.3 \%)$ \\
\hline $\mathrm{F}$ & 4 & 4 & 0 & 78 & 13 & $3(3.8 \%)$ \\
\hline G & 6 & 6 & 0 & 27 & 13.5 & $5(18.5 \%)$ \\
\hline $\mathrm{H}$ & 3 & 1 & 2 & 52 & 13 & $25(48.1 \%)$ \\
\hline I & 5 & 5 & 0 & 90 & 15 & $4(4.4 \%)$ \\
\hline J & $5^{*}$ & 5 & 1 & 135 & 15 & $4(3.0 \%)$ \\
\hline K & 4 & 4 & 0 & 62 & 15.5 & $4(6.5 \%)$ \\
\hline $\mathrm{L}$ & 2 & 2 & 0 & 45 & 15 & $1(2.2 \%)$ \\
\hline$M$ & $4 *$ & 4 & 2 & 32 & 16 & $4(12.5 \%)$ \\
\hline N & $3^{*}$ & 3 & 1 & 30 & 7.5 & $2(6.7 \%)$ \\
\hline $\mathrm{O}$ & 6 & 3 & 3 & 90 & 18 & $19(21.1 \%)$ \\
\hline$P$ & 13 & 11 & 2 & 174 & 13.4 & 26 (14.9\%) \\
\hline$Q$ & $3^{*}$ & 2 & 2 & 58 & 14.5 & $21(36.2 \%)$ \\
\hline $\mathrm{R}$ & $3 *$ & 3 & 1 & 48 & 12 & 7 (14.6\%) \\
\hline$S$ & $6^{\dagger}$ & 4 & 1 & 89 & 12.7 & $21(23.6 \%)$ \\
\hline TOTAL & & & & 1323 & 13.5 & 210 (15.9\%) \\
\hline
\end{tabular}

*students that ticked more than one location for patient recruitment; †Two students also recruited patients from the community 